\title{
An Analysis of China's Higher Education Public Policy “College Students Can Suspend Study to Start up Businesses"
}

\author{
Tao Jiang, Fang Zhou \\ The School of Public Finance and Public Administration, Jiangxi University of Finance and Economics, Nanchang, China \\ Email: ruthzjleni@163.com
}

How to cite this paper: Jiang, T. and Zhou, F. (2017) An Analysis of China's Higher Education Public Policy "College Students Can Suspend Study to Start up Businesses". Open Journal of Social Sciences, 5, 272-281. https://doi.org/10.4236/jss.2017.58022

Received: August 7, 2017

Accepted: August 27, 2017

Published: August 30, 2017

Copyright $\odot 2017$ by authors and Scientific Research Publishing Inc. This work is licensed under the Creative Commons Attribution International License (CC BY 4.0).

http://creativecommons.org/licenses/by/4.0/ c) (i) Open Access

\begin{abstract}
In recent years, the number of college graduates in China has been increasing rapidly and has reached several new highs. Therefore, the employment situation of college students in China is becoming increasingly grim, drawing wide attention and concern from all walks of life in society. The Ministry of Education officially put forward the policy of College Students can Suspend Study to Start Up Businesses in 2016. The policy is in favour of universities and colleges adopting flexible schooling systems, lengthening students' school years on campus, allowing students to adjust their academic progress to start up their businesses while retaining their student identity. This article is written in the purpose of analyzing the policy from the perspectives of public policy-making methodologies, procedures and the backgrounds against which the policy was made, weighing its pros and cons and its practicality and offering some suggestions concerning it to make the policy more applicable and effective.
\end{abstract}

\section{Keywords}

Public Problem, Policy Problem, Policy Making, College Students, Suspend Study to Start up Businesses

\section{Introduction}

Since the expansion of higher education began to take place in China in 1998, the scale of higher education has been increasing rapidly, leading to a gigantic number of students and a much tougher employment situation for the graduates. Thus, the Policy of College Students Can Suspend Study to Start Up Businesses was formulated and promulgated against the background of increasingly tense employment situation for college graduates, which concerns vast 
numbers of people and different classes and has huge influences over a country's economy, technology, national defense and society, etc.

The aim of this paper is to try to analyse, from the perspective of the backgrounds of the problem and related national policies, how the problem of "College students can suspend study to start up businesses" was qualified to be a public problem and a pubic policy problem according to the micro-procedures of public policy making, as well as how final policies were made and are being implemented and make some suggestions in the end.

\section{General Situation}

The academia circle normally considers the definition of public problem put forward by Cobb and Elder in 1983 authoritative-"Public problems are neither simple established facts nor problems reflecting the status quo, but are still explaining and societal definition situations." Therefore, the definition of public problem and it itself are by no means objective, with them neither a linear nor a determinative but a dynamic process. The problem of college graduates' employment is a public problem that has been attracting wide attention and concern from the people, the government and our country, so it is both a realistic and social problem. At present, the situation is by no means more optimistic, with more graduates than needed and the competition from the past graduates and oversea returnees. The declining education quality is also to blame, with quite a few college students being unable to meet the demands and standards set by their employers or find jobs that match their majors.

If left unattended without any measures to be taken by relevant parties, the problem will definitely incur serious consequences. Firstly, people's trust in higher education will be reduced, resulting in less enthusiasm about investing in higher education. Worse still, higher education will likely be undermined because it has to cater to the market and employment demands (Cui Yuting, Zhao Fanghui, 2010) [1].

Secondly, college graduates are supposed to become major groups of consumers, so their having trouble finding jobs will also hinder our country's domestic consumption policy from progressing smoothly. Thirdly, constant complaints and dissatisfaction from college students and their parents who constitute a large portion of the entire population will pose potential threats to our society, crimes and disruptions of riots (Wang Wei, 2004) [2].

Therefore, with all that has been mentioned above, we can see the problem of college students' employment is also a public policy problem, because a public problem important enough to attract attention from the government and concern and anxiety from vast majority of ordinary people can become a public policy problem (Xie Ming, 2010) [3]. Some people even chose to protest against the relevant departments or the government in a less pleasant manner. Meanwhile, frequent media reports also serve as a strong catalyst. More importantly, its solution lies within the government's capability, which guarantees it the pos- 
sibility of turning the solution into a public policy.

Actually, the State Council Office forwarded the Ministry of Education's NOTICE in Mar. 2002, which stipulates that relevant departments should simplify the formalities, increase working efficiency and actively support entrepreneurship of college students. Emloyment-guiding courses should be opened to enhance college students' ideological and political education, to help them form the concept of selecting jobs by themselves, starting up their own businesses and taking seeking employment seriously.

Therefore, it is apparent that the public policy problem of college graduates' employment garnered great attention from a long time ago from the Ministry of Education, which has also contributed to the formulation and promulgation of relevant policies supported and approved by the State Council. It was under this circumstance that College Students Start Up Their Own Businesses became one of the most preferred measures taken to alleviate employment pressure and solve related problems in this regard.

\section{Analysing from the Micro-Procedure of Public Policy Making}

However, public problems possess the characteristics of complexity, unclear structure, dynamism, multiple-conclusiveness and polytrope, with dynamic evolution the most fundamental one. Every element or system comprising a public problem is changing and evolving with every second passing by in not mechanic and linear but a non-linear way. Meanwhile, every element or system is influencing other elements or systems, making a public problem constantly evolve in a non-linear way as time goes by (J. W., 2003) [4].

A public policy problem is one that concerns almost every individual at a certain period of time, that is, a public problem is closely linked to the cognition, values and interests of every individual. This implies that the natural, ecological, social, historical and psychological factors will all be embedded into a public problem just like that of an individual. Furthermore, all the factors above are intermingled with each other. Therefore it is extremely vital to know and analyse the new characteristics and nature of the public policy problem of College Students' Employment in this modern era, which, to a great extent, determines whether a scientific, effective and successful policy will be made. Here in this paper, the work is done from the perspective of the micro-procedure of public policy making.

\subsection{The Nature of a Policy Problem}

\subsubsection{Complexity}

Just as stated above, a policy problem is scarcely an isolated, unilateral and purely one-aspect problem. It is a chaotic mess. Likewise, the policy problem of College Students' Employment is definitely closely connected with the social background. economic development, population, people's cognitive ability, interests and demands, etc at a given period of time. 
1) Population:

In recent years, the number of college students enrolled across universities and colleges in China has been increasing rapidly. There were some 6.8 million college graduates in 2012, 6.99 million in 2013, while the number reached 7.27 million in 2014 and 7.49 million in 2015 (China Youth Daily, 2014) [5]. Obviously, the increasing number means greater employment pressure, which made it even more essential and urgent to formulate and promulgate better and more effective policies.

2) Society:

College students' entrepreneurship-related policies have been attracting enormous attention and heated debated among the society. As time goes by, people's perception of entrepreneurship has changed remarkably. With increasing reports from media and relevant departments covering inspiring entrepreneurship and successful cases, the general public's old notion of holding a stable job or "Golden bowl" is not as deeply rooted (Xinhua News, 2012) [6]. As a matter of fact, more people nowadays have changed their attitude towards entrepreneurship, with the interpretation of "labeling it as misconduct" changed into "it being a symbol of an entrepreneur". In addition to a more tolerant attitude, the support and encouragement from the society also creates a sound environment and atmosphere for college students' entrepreneurship.

3) Provincial and municipal universities and colleges:

More and more province and city-level universities and colleges have improved their related measures, providing more professional and reliable entrepreneurship guidance for college students. For instance: The entrepreneurship act in Zhejiang University is not initiated by individuals but by teams, thus making up for the shortcomings of starting up businesses by merely individuals. Meanwhile, the approach of combining the integrated strengths of student entrepreneurs on campus and mentors outside the campus has also proved effective and popular, with celebrities from the province and others from the business circle nationwide contributing, such as Mr. Xu Xiaoping and Mr. Yu Minhong from New Oriental, the co-founders of China's biggest private language training school (Zhang Baomin, 2013) [7].

In terms of the school educational system, Zhejiang University also adopted a more flexible one that allows students who are starting up their businesses to be absent from classes and learn by themselves or through teachers' instructions and take the exams in the end. There is also the practice of lengthening the school educational system that allows students to finish their study from 4 years to 6 years. Such attempts as this have also been adopted in quite a few other universities nationwide to benefit students.

For instance, in Jan. 2013, the Shandong Provincial Government published a document, in which it encourages universities and colleges in the province to allow their full-time students to Start Up Businesses while suspending studies temporarily. Furthermore, similar policies had been announced in Tianjin City 
and Jiangsu Province, etc. Quite a few successful cases of entrepreneurship have also proved that actually starting up businesses and study are not contradictory with each other (Xinhua News, 2012) [6].

4) Economy:

After 2014, Chinese economy shifted towards the New Normal, changing from "High growth" to Medium-high growth and "Improve quality, and make progress while ensuring stability".

\subsubsection{Human Factors}

Policy problems can also be said to be results of people's subjective judgments. Different countries have different criteria due to the different national circumstances, different cultural values and perceptions, different experience and methods. Therefore, people in different countries will resort to different explanations according to their specific needs.

1) Dynamism

The feature above thus leads to a policy problem being dynamic, with its content and solutions changing with the advancement of time and space.

2) Historic influence

A public policy problem doesn't just occur abruptly but rather is a product of the development and evolution of another problem with all its history and basis playing an important role (David A. Rochefort and Roger W. Cobb., 1993) [7].

So it is fair to say that any new public policy problem is the derivative of a past problem, or one created by the changes in the environment and other elements. Naturally, the theory also applies to the problem of "College students' employment". After the first series of policies supporting college students' starting up their businesses have been in place for more than 10 years, the problem has undertaken some new features and characteristics, thus resulting in a new public policy problem.

Admittedly, the policies supporting college students' independent entrepreneurship emerged from none to some, then developing in quantity and quality. Apart from relevant policies, the number of related courses and services initiated by universities and colleges has been increasing. For instance, quite a few universities have established venues for practising entrepreneurship, such as Exemplary Base of Entrepreneurship within campus, and Entrepreneurship Garden to provide a practice platform for college students' independent entrepreneurship. It is also a fact that the traditional idea of employment of college students has changed and that their awareness of starting up businesses has been stimulated, with their desire for entrepreneurship more intense and motivation more robust.

However, despite all this, there still exist many problems in this regard. For instance, there is still great room for improvement in these policies, which will still inhibit students from starting up their businesses. There are still problems with the arrangements of relevant courses and lecturing. The college students are not well prepared enough. The social participation is relatively low so it is hard to put certain activities into practice. The number of college graduates in 2014 
was 7.27 million, reaching a historic new high. However, the effects of employment-targeted entrepreneurship policies and a series of other supportive measures were little. According to the vice minister of the Bureau of Human Resources and Social Security, Mr, Xin Changxing, the percentage of students choosing to start up their businesses only accounted for 1 percent of the total, a far smaller figure compared with those of other countries (China Youth Daily, 2014) [5].

Of course, in the process of constructing a public policy problem, the constructing methods are very critical. Dunn believes that "the constructing method of a public problem comes ahead of the solutions, ... in that the former is more advanced in essence." (William N. Dunn., 2004) [8] For instance, Supposition Analysis, Boundary Analysis, Brainstorming Analysis and Cause-Effect Analysis as well as SWOT Analysis approaches can be adopted.

\subsection{Affirming the Goals of the Policy}

Promulgate and put into effect more effective national policies supporting college students' independent entrepreneurship and further enhance their interest and awareness, improve their capabilities of starting up businesses and innovation to increase the general employment rate and promote the economic and technological development of our country.

\subsection{Drafting, Assessing and Selecting Proposals}

Special agencies and specialists in the areas of education, management, administration, economics and sociology, etc can be gathered to work on the procedure with large amounts of research work to be done in advance. Different proposals should be made to serve as alternatives and the screening of these alternatives is a process of identifying the best one based on a full assessment of these alternatives.

\subsection{The Legitimization of the Policy}

After screening the alternative proposals comes the final round of deciding on the best one, which is conducted on the basis of assessment and proof of the alternative proposals. The screening procedure is the prerequisite for deciding on the final best one, a strict procedure that must be completed by the authoritative department with the final step to be accomplished by the top legislature through voting. What's worth attention is that after the legitimization of the policy, communication, implementation and assessment work of the policy should be conducted (Anders Hanberger, 2001) [9]. The communication work of a public policy refers to the act of coordinating different stakeholders in the process of promulgating and implementing the policy to achieve the preset goals. The implementation of a policy mainly focuses on the implementing situation of the legitimate policy to achieve the goals. Once inadequate implementation or poor effects are discovered which will prevent the goals from being met, adjustments 
and urgent measures should be adopted. The assessment of a policy refers to the assessing of the performance and value of the promulgation, implementation, functioning, effectiveness, effect, efficiency of the policy as well as public feedback. The main assessment approaches include: Investigation, survey, Data analysis, All-around assessment, Sample assessment, General investigation, Individual interview, and Public poll.

\section{Analysis of the Effects of the Policy}

\subsection{The Advantages of the Policy}

4.1.1. College Students' Starting up Businesses Is Good for Employment The employment pressure for college students has been increasingly tense in recent years, thus becoming a major concern in society. The phenomenon that graduation means being out of employment is common and the phenomenon of boomrang kids(young people who are not currently engaged in Employment, Education or Training but rely on their parents for a living) is also gathering momentum. The policy that College Students Can Suspend Study to Start Up Businesses can relevantly improve employment in that it allows students to participate in social practices in advance, integrate what they learned in the practices with campus study after their return, bringing the synergy of theory and practice to the maximum and not only helping solve their own employment problems but also creating job opportunities for others (Cui Yuting, Zhao Fanghui, 2010) [1].

According to statistics, the number of college students involved in starting up their own businesses kept climbing consecutively from 2014 to 2016 . The number of college students who started up businesses in 2014 was 478,000,597,000 in 2015 and 615,000 in 2016.

\subsubsection{The Policy Is Conducive to Cultivating Students' Independence and Innovative Capabilities}

Exam-oriented education has made quite a few students lack the ability to live, work and learn independently and rely on teachers and parents' intensive care because they simply lack the ability to get things done by themselves, not to mention to be innovative.

\subsubsection{The Policy Is Beneficial for Cultivating Personalized Talents and Promoting the Process of Educational Modernization}

A flexible school system enables the students to choose flexible schedules and different learning approaches in order to balance between study and entrepreneurship. Every student can choose different subjects to complete credit requirement according to their own specific needs and preferences, thus avoiding the previous homogeneous, monotonous and rigid education model that everyone has to accept.

\subsection{The Disadvantages of the Policy}

Though a flexible school system can provide students with the possibility of ba- 
lancing both study and entrepreneurship, many problems still exist at this initial stage of implementation, such as: concrete arrangements of curriculum, credit arrangements and school system arrangements, etc. Furthermore, a school system and curricular arrangement that are compatible with the policy should be very well-conceived, which also takes time to test, verify and improve.

The policy might become the excuse for students to drop out or lose interest in study and academic research. As a matter of fact, there have been some students who are frequently absent from classes deliberately under the pretext of engaging in their businesses while lowering their standards for academic courses, with many asking for a pass for exams.

Things have proved that some disciplines have advantages in terms of entrepreneurship, such as Electronics, E-commerce, Design and some creativity-related majors. These majors require relatively smaller fund to start up a business and cover wider ranges of projects, and have relatively lower thresholds for the resources accumulated, thus becoming very popular choices for college students who want to start up their own businesses. However, students in some other majors, such as English, may find it harder to establish a business in that the majors themselves restrict the areas the students can enter or the market demand for these areas have greatly decreased. The standards for other majors, such as Finance and Law, of starting up a business in the sector are higher than the students can meet. Even though some of them may manage to start up a business, it is difficult to press ahead and make accomplishments. What follows failures will most likely be a waste of money, time and energy, and worse still, frustration and even pessimism.

According to a survey conducted by a newspaper to 850 college students,237 of them have thought about starting up their businesses; 204 plan to get involved after graduation; Only 20 of them are currently engaged in entrepreneurship, most of them in networking and catering industries as part-timers; The rest simply don't know much about the College Students Can Suspend Study to Start Up Businesses Policy. Even after being informed of the policy, only 63 are supportive of it while $92.6 \%$ say they will never make the choice of suspending their studies to start up a business.

\section{Suggestions}

\subsection{The Government}

The Ministry of Education should promulgate more supportive laws and regulations and urge all universities and colleges involved put relevant policies in place. The local governments should streamline administration and distribute power to the lower levels, be more supportive of college students' entrepreneurship, provide more preferential policies to reduce obstacles and difficulties for college students who want to start up their businesses. For instance, the central and local government can mobilize social forces to set up some entrepreneurship bases to serve and aid the students, providing them with funding, projects and 
guidance.

\subsection{Universities and Colleges}

Universities and colleges should properly optimize their curriculum and provide a variety of lecturers on entrepreneurship through different channels and from all-around angles. They should play a leading role at the initiating stage and make reasonable and specific course arrangements for students involved in entrepreneurship according to students' needs. In addition, college institutions can also invite experienced experts regularly to give guidance and training to the students, as mentioned in the paper of the practice already adopted by some universities.

\subsection{The Public}

People's perception of entrepreneurship should be changed. As stated previously, traditionally, most people hold the notion that students' only task is to work hard and that they shouldn't spend time on unrelated things in college. However, people's perception needs to be changed under different social backgrounds and more tense employment situation. Therefore, young people should be encouraged to enter the society bravely. In this regard, the media and communities can help spread the new perception to the public and attract their attention and support.

Meanwhile, parents should also view suspending study to start businesses rationally and provide help in the process when necessary.

\subsection{Students}

Students should make their own sound judgments about entrepreneurship and shouldn't follow the mainstream blindly. Not everyone is suitable to try the initiative. Once decisions have been made, the practitioners should take advantage of their own strengths, enhance the learning of related knowledge and actively seek for valuable entrepreneurship projects. At the same time, they can also learn from experience and practices of other students or entrepreneurs. Therefore, suspending study to start businesses doesn't mean ceasing learning but keeping learning and holding a good and earnest attitude.

\section{Conclusions}

It would be reasonable for different students to carefully decide, depending on their individual case, whether they want and are able to suspend their studies to start up a business. While the intention of the policy is good, not every student is fit and eligible for it. Prior to making the decision, one should get as much information as possible on the essence, spirit, requirements and qualifications needed and rationally analyse if he or she is qualified enough to leave campus and be a social member temporarily. It would be unwise to just follow the mainstream or merely long to escape from college life and become a so-called entre- 
preneur.

Though the Policy "College Students Can Suspend Study to Start Up Businesses" has been put into effect and is being implemented, the problems of college students' employment and entrepreneurship can't be solved by merely a document. It takes time before problems on the ensurance, procedure and effects of implementation can be observed. At the same time, the government should also continue relevant studies, come up with specific supportive laws and regulations to make the policy more consistent and sustainable and realize the goal of benefiting those following the policy to a greater extent.

\section{References}

[1] Cui, Y.T. and Zhao, F.H. (2010) The Dilemma of University Entrepreneurship. Education and Occupation, 25.

[2] Wang, W. (2004) Research on the Mode of College Students' Entrepreneurship. Jilin University, Jilin.

[3] Xie, M. (2010) An Introduction to Public Policy. China Renmin University Press.

[4] Kingdon, J.W. (2003) Agendas, Alternatives, and Public Policies. 2nd Edition, Addison-Wesley Longman Inc., Boston.

[5] (2014) Ministry of Education: Allow Students to Suspend Study to Start up Business, Allow Colorful Growth. China Youth Daily.

[6] (2012) Jiangsu Province: College Students' Suspending Study to Start up Businesses Can Open “Another Door” of Employment. Xinhua News.

[7] Rochefort, D.A. and Cobb, R.W. (1993) Problem Definition, Agenda Access, and Policy Choice. Policy Studies Journal, 21.

[8] Dunn, W.N. (2011) Public Policy Analysis, an Introduction. China Renmin University Press.

[9] Hanberger, A. (2001) What Is the Policy Problem? Methodological Challenges in Policy Evaluation. Evaluation, 7.

\section{Scientific Research Publishing}

Submit or recommend next manuscript to SCIRP and we will provide best service for you:

Accepting pre-submission inquiries through Email, Facebook, LinkedIn, Twitter, etc. A wide selection of journals (inclusive of 9 subjects, more than 200 journals)

Providing 24-hour high-quality service

User-friendly online submission system

Fair and swift peer-review system

Efficient typesetting and proofreading procedure

Display of the result of downloads and visits, as well as the number of cited articles

Maximum dissemination of your research work

Submit your manuscript at: http://papersubmission.scirp.org/

Orcontact jss@scirp.org 